\title{
Prevalence of Renal Stones and Complications in Study Population: A Clinical Study
}

\author{
Surendra Mehrotra ${ }^{1 *}$, Abhay Krishna ${ }^{2}$ \\ ${ }^{1 *}$ Assistant Professor, 2Associate Professor, Department of General Surgery, \\ Mayo Institute of Medical Sciences, Safedabad, Barabanki, Uttar Pradesh, India.
}

\begin{abstract}
Background: Chronic kidney disease is a complication of kidney stones as a result of rare hereditary disorders. The present study aimed at evaluating the types of renal stones and complication in patients of nephrolithiasis.

Materials \& Methods: This study was conducted in department of general surgery in 2014. It included 310 patients of renal stones that had renal pain. Patients's details such as age, gender, type of stones, calcium, phosphorus, parathyroid hormone (PTH), urine analysis in terms of calcium, oxalate, uric acid, sodium nitrate, uric were recorded. The presence of renal stones was confirmed by ultrasonography.

Results: Total patients were 310 which include males (190) and females (120). The mean level of calcium in both males and females was $8.06 \pm 0.20$ and $8.24 \pm 0.19$ respectively. Phosphorus level was $4.58 \pm 0.26$ in males and $4.18 \pm 0.24$ in females. PTH was 35.42 and $35.04 \pm 13.13$ in males and females respectively. Uric acid was 4.22 in males and $4.68 \pm$ 1.78 in females. The difference was non - significant. However, creatinine level was significantly higher in males (1.52 \pm 1.42$)$ as compared to females $(1.26 \pm 0.98)(p-0.02)$. BUN was also significantly higher in males. (P- 0.03)
\end{abstract}

\section{INTRODUCTION}

Chronic kidney disease (CKD) is becoming a major public health problem worldwide. The current burden of disease might due to a change of the underlying pathogenicity of CKD. ${ }^{1}$

Earlier stages of CKD are defined based on the combination of kidney damage and decreased kidney function. The National Health and Nutrition Examination Surveys (NHANES) have provided a rigorous basis for estimating CKD prevalence. These large nationally representative surveys conducted by the National Center of Health Statistics (NCHS) include a laboratory assessment of albuminuria and serum creatinine allowing for identification and staging of CKD regardless of the participant or their physician's awareness. ${ }^{2}$

CKD is a complication of kidney stones as a result of rare hereditary disorders. Glomerulonephritis was the one of the leading causes of kidney disease several decades ago. Nowadays, infections have become a less important cause for kidney disease, at least in the western world. Moreover, current
Conclusion: Author concludes that renal stones are one of the causes of end stage renal failure. Thus careful evaluation of renal function test is necessary to prevent the condition.

Key Words: Chronic kidney disease, Calcium, Phosphorus, Parathyroid hormone.

\section{*Correspondence to:}

\section{Dr. Surendra Mehrotra}

Assistant Professor,

Department of General Surgery,

Mayo Institute of Medical Sciences,

Safedabad, Barabanki, Uttar Pradesh, India.

\section{Article History:}

Received: 12-01-2015, Revised: 27-06-2015, Accepted: 14-11-2016

\begin{tabular}{|l|c|}
\hline \multicolumn{2}{|c|}{ Access this article online } \\
\hline $\begin{array}{l}\text { Website: } \\
\text { www.jjmrp.com }\end{array}$ & \\
\hline Dol: & \\
10.21276/ijmrp.2016.2.6.022 & \\
\hline
\end{tabular}

evidence suggests that hypertension and diabetes are the two major causes of kidney disease worldwide. Kidney stones and chronic kidney disease (CKD) were reported in $5 \%$ and $13 \%$ of the adult population..$^{3,4}$

Kidney stones may be associated with complications such as infection, acute renal failure (due to obstructive uropathy), and chronic kidney damage. The prevalence of the end-stage renal disease (ESRD) due to kidney stones among patients who start maintenance hemodialysis was approximately $3.2 \%$. Infection stones are the most frequent cause of urolithiasis associated ESRD especially in bilateral developing of stag horn stones configuration. Extensive stone development has been observed with uric acid, calciumoxalate or cystine stones. ${ }^{4}$ The exact mechanism of progressive renal failure has not yet completely recognized, even with well-known obstructive and infections mechanisms of kidney injury crystal deposition in the tubules and interstitium of both kidneys. The potential risk of degradation of 
renal function justifies the etiological investigation of all lithiasis associated pathologies. ${ }^{5}$ Thus, calculus analysis of the crystalline phases and morphological characteristics is an important factor in the etiological diagnosis of the disease. Hence, the aim of this study was to investigate renal stones complications in present population.

\section{MATERIALS \& METHODS}

This study was conducted in department of general surgery in 2014. It included 310 patients of renal stones that had renal pain. Patients's details such as age, gender, type of stones, calcium, phosphorus, parathyroid hormone (PTH), urine analysis in terms of calcium, oxalate, uric acid, sodium nitrate, uric were recorded. The presence of renal stones was confirmed by ultrasonography. Blood biochemical examinations were performed based on the type and the number of stones.

Results thus obtained were subjected to statistical analysis with the help of SPSS. In all investigated cases, the results have been known statistically significant in the case of $P \leq 0.05$.

\section{RESULTS}

Total patients were 310 which include males (190) and females (120) (Table 1). In evaluated patients, the mean level of calcium in both males and females was $8.06 \pm 0.20$ and $8.24 \pm 0.19$ respectively. Phosphorus level was $4.58 \pm 0.26$ in males and 4.18 \pm 0.24 in females. PTH was 35.42 and $35.04 \pm 13$.13 in males and females respectively. Uric acid was 4.22 in males and $4.68 \pm$ 1.78 in females. The difference was non - significant.

However, creatinine level was significantly higher in males (1.52 \pm $1.42)$ as compared to females $(1.26 \pm 0.98)(p-0.02)$. BUN was also significantly higher in males. ( $p-0.03)$

The recurrent infections were more commonly seen in males (14) as compared to females (4) (P-0.01). More number of staghorn stones was seen in males. Number of hemodialysis cases was 4 in males and no case was recorded in females. Surgeries were performed in 5 males.

Graph 1(a,b,c) shows level of calcium, phosphorus, PTH, uric acid, creatinine and BUN in calcium oxalate, calcium phosphate, uric acid, struvite and mixed type of stones.

Table 1: Demographic Data of Patients

\begin{tabular}{lccc}
\hline & \multicolumn{2}{c}{ TOTAL - 310 } & \\
\hline SEX & MALE & FEMALE & P VALUE \\
NUMBER & 190 & 120 & 0.1 \\
AGE & $45.07 \pm 11.26$ & $40.02 \pm 17.02$ & 0.9 \\
CALCIUM & $8.06 \pm 0.20$ & $8.24 \pm 0.19$ & 0.8 \\
PHOSPHORUS & $4.58 \pm 0.26$ & $4.18 \pm 0.24$ & 0.5 \\
URIC ACID & $4.22 \pm 1.82$ & $4.68 \pm 1.78$ & 0.3 \\
PTH & $35.42 \pm 12.26$ & $35.04 \pm 13.13$ & 1 \\
RECURRENT INFECTION & 14 & 4 & 0.01 \\
STAGHORN STONE & 8 & 1 & 0.2 \\
CREATININE & $1.52 \pm 1.42$ & $1.26 \pm 0.98$ & 0.02 \\
BUN & $18.62 \pm 11.48$ & $15.56 \pm 8.90$ & 0.03 \\
HEMODIALYSIS & 4 & 0 & 0.26 \\
SURGERY & 5 & 0 & 0.21 \\
\hline
\end{tabular}

Graph 1 (a): Comparison of the Measured Blood Markers in Patients Based on the Type of Stone

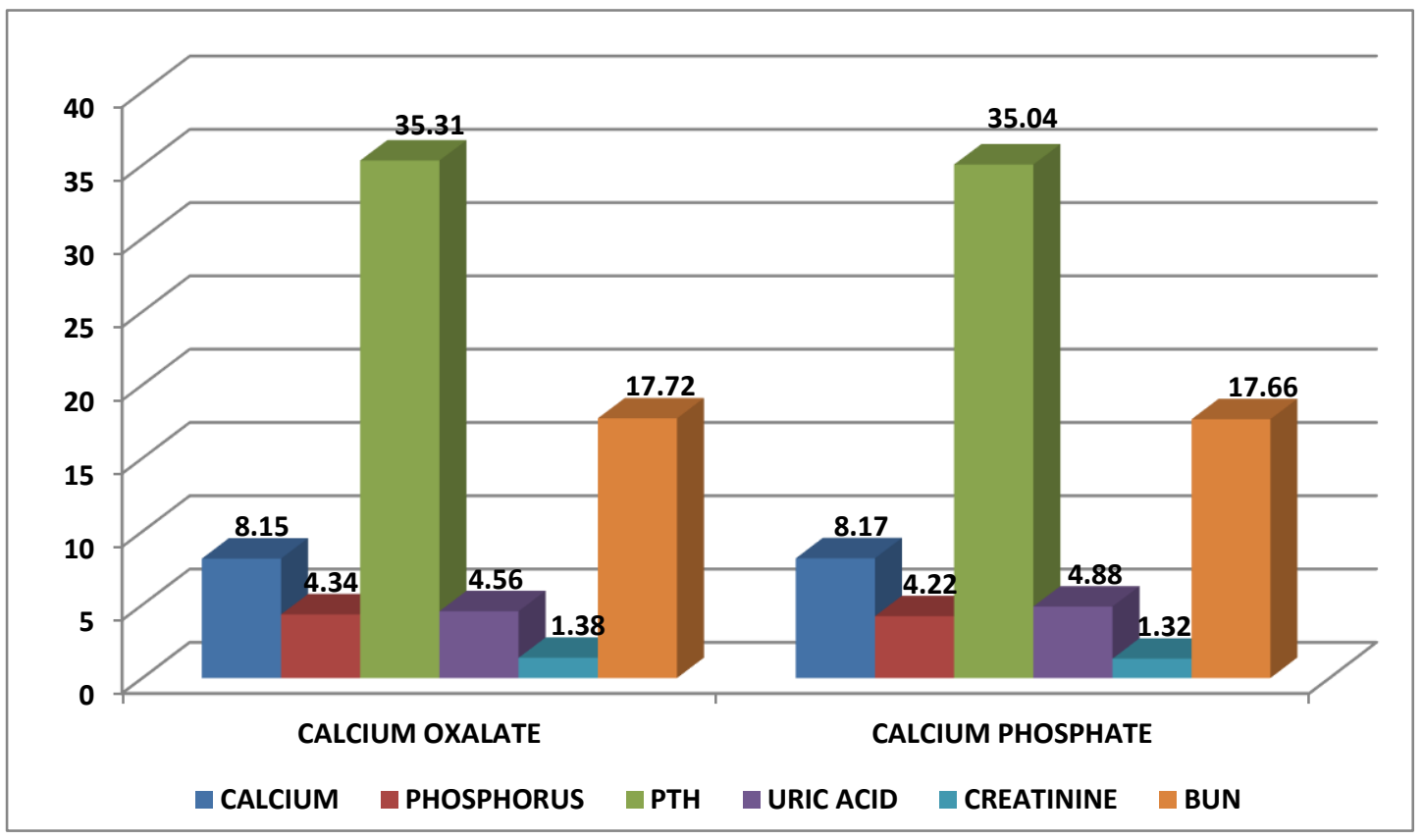


Graph 1(b): Comparison of the Measured Blood Markers in Patients Based on the Type of Stone

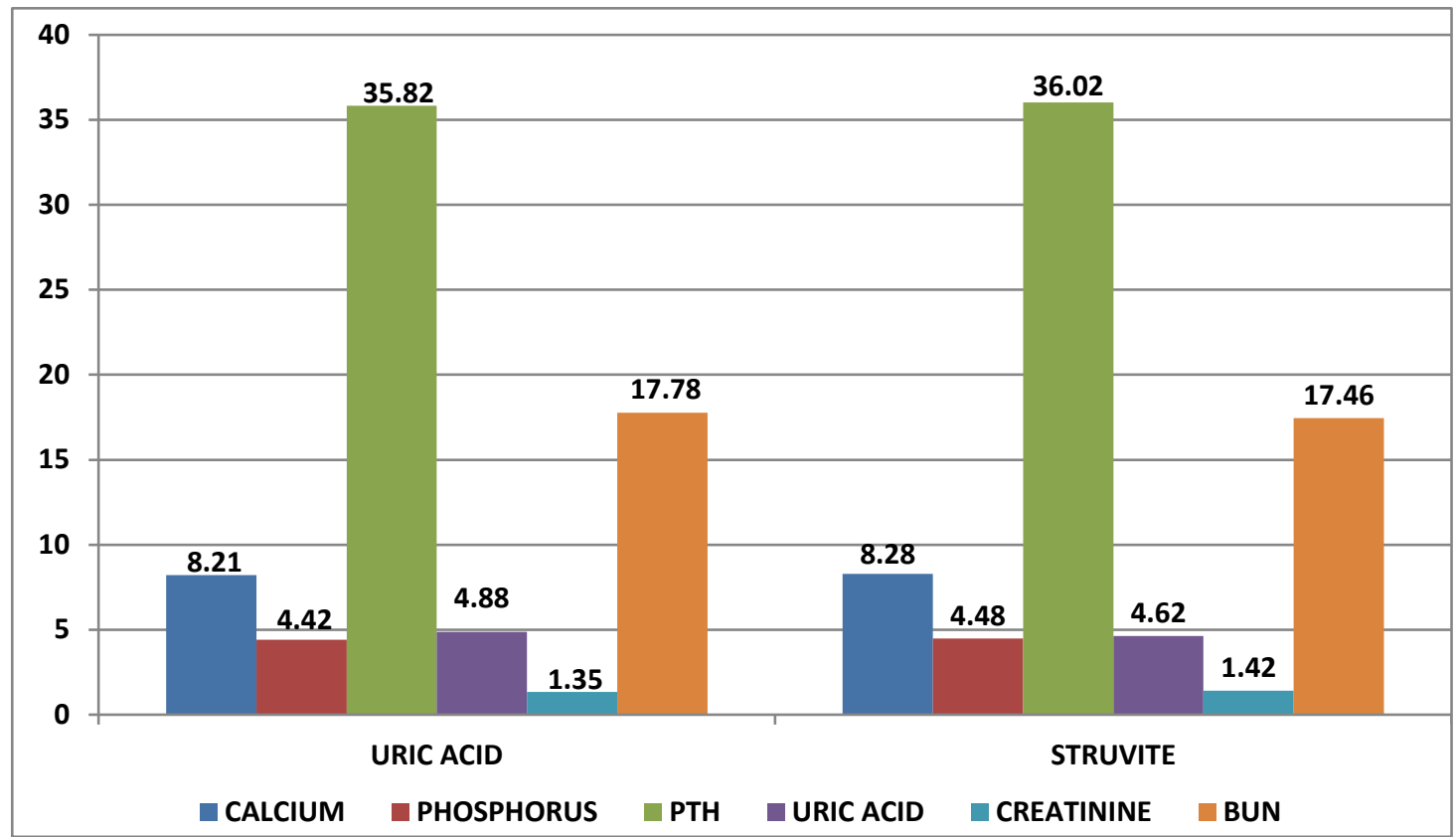

Graph 1(c): Comparison of the Measured Blood Markers in Patients Based on the Type of Stone

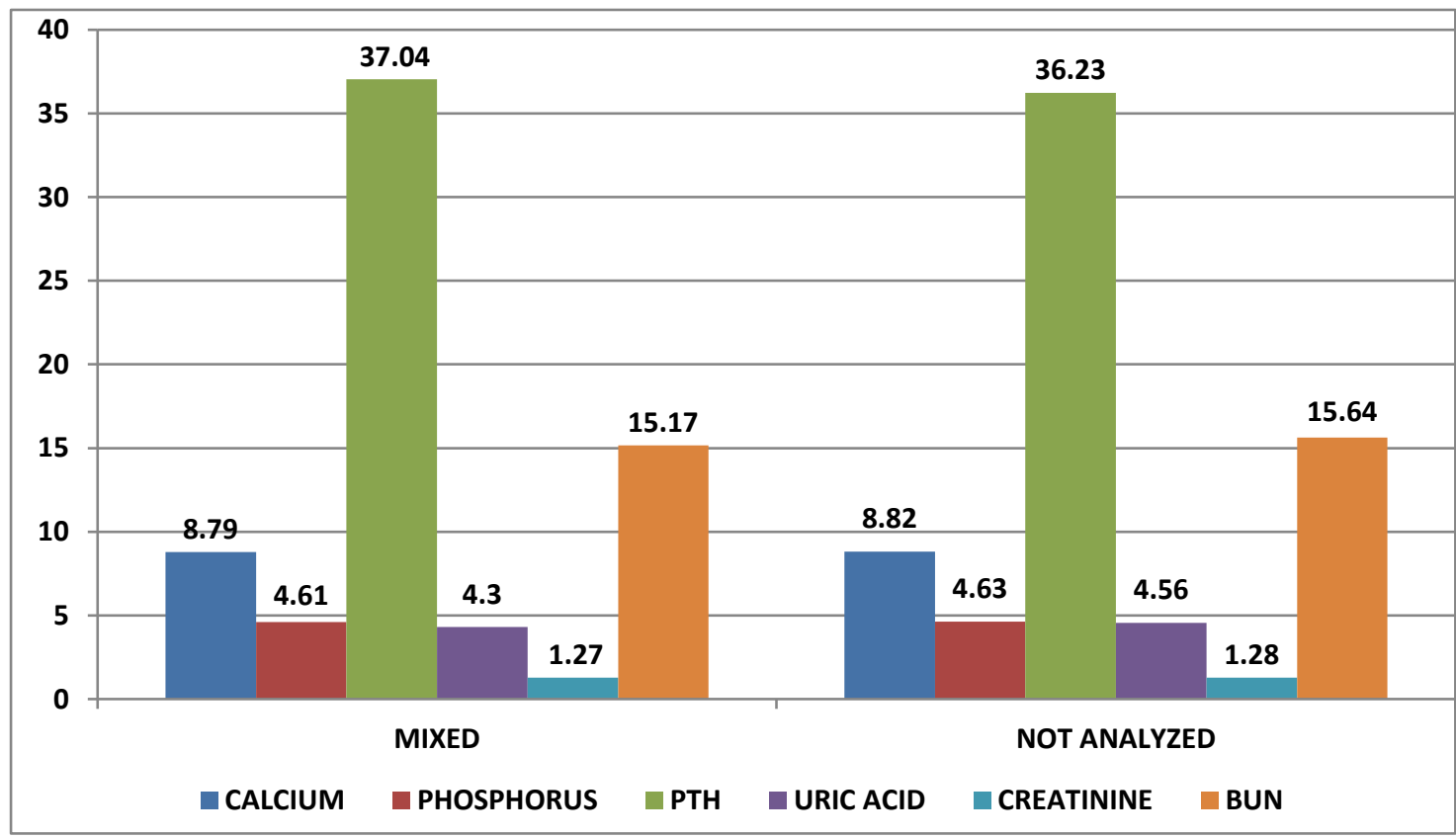

\section{DISCUSSION}

Chronic kidney disease (CKD) is emerging to be an important chronic disease globally. One reason is the rapidly increasing worldwide incidence of diabetes and hypertension. In India, given its population $>1$ billion, the rising incidence of CKD is likely to pose major problems for both healthcare and the economy in future years. Indeed, it has been recently estimated that the ageadjusted incidence rate of ESRD in India to be 229 per million population. 6

In present study, total patients were 310 which include males (190) and females (120). The difference was not significant. Other studies revealed significant difference.

We evaluated calcium, phosphorus, uric acid, PTH level in patients. The difference was not significant among males and females.
The mean age in our study was much lower than Oussama et al ${ }^{7}$ and Coe et $\mathrm{al}^{8}$ studies. In our study, there was male predominance. It is in agreement to study by Gupta M et al. ${ }^{9}$

It is reported that the calcium oxalate stones were the most common type of urinary stones in men and women, we showed that incidence of this kind of stones was more.

Foley et al ${ }^{10}$ reported more incidence of hemodialysis in patients with renal stones. However in our study, we reported 4 cases in males. The lesser incidence may be due to small population size. Jungers et al. ${ }^{11}$ also reported that the overall contribution of nephrolithiasis lead to end stage renal disease (ESRD) was 3.2\%. In Gupta et al. study on 2000 patients with nephrolithiasis, only 33 patients $(1.7 \%)$ had mild to moderate renal failure. In our study the impaired renal function level was very low. 
In our study, 5 patients had a history of surgery. So it seems that immediate intervention is necessary in patients with nephrolithiasis that showed symptoms of renal failure.

In present study, we evaluated the type of stones. The most common types were calcium oxalate, calcium phosphate, uric acid, struvite and mixed variety.

The level of calcium acetate stone was low in our study. Marengella et a ${ }^{12}$ reported $18 \%$ of prevalence rate.

The prevalence of uric acid stones in various studies has been reported in $7.2-15.3 \%$ of cases. This value in Oussama et al. and Jungers et al. was 17.8 and $18.0 \%$ respectively. In our study the prevalence was low.

\section{CONCLUSION}

Author concludes that renal stones are one of the causes of end stage renal failure. Thus careful evaluation of renal function test is necessary to prevent the condition.

\section{REFERENCES}

1. Stamatelou KK, Francis ME, Jones CA, Nyberg LM, Curhan GC. Time trends in reported prevalence of kidney stones in the United States: 1976-1994. Kidney Int. 2003; 63: 1817-23.

2. Coresh J, Selvin E, Stevens LA, Manzi J, Kusek JW, Eggers P, et al. Prevalence of chronic kidney disease in the United States. J. Amer. Dent. Assoc. 2007; 298: 2038-47.

3. Frymoyer PA, Scheinman SJ, Dunham PB, Jones DB, Hueber $P$, Schroeder ET. X-linked recessive nephrolithiasis with renal failure. N Engl J Med. 1991; 325: 681-6.

4. Leumann EP. Primary hyperoxaluria: an important cause of renal failure in infancy. Int J Pediatr Nephrol 1985; 6: 13-6.

5. Gambaro G, Favaro S, D'Angelo A. Risk for renal failure in nephrolithiasis. Am J Kidney Dis 2001; 37: 233-43.

6. Ramello A, Vitale C, Marangella M. Epidemiology of nephrolithiasis. J Nephrol. 2000; 13:45-50.
7. Oussama A, Kzaiber F, Mernari B, Hilmi A, Semmoud A, Daudon M. Analysis of urinary calculi in adults from the Moroccan Medium Atlas by Fourier transform infrared spectrophotometry. Prog Urol. 2000; 10: 404-10.

8. Coe FL, Evan A, Worcester E. Kidney stone disease. J Clin Invest. 2005; 115: 2598-608.

9. Gupta M, Bolton DM, Gupta PN, Stoller ML. Improved renal function following aggressive treatment of urolithiasis and concurrent mild to moderate renal insufficiency. J Urol. 1994; 152: 1086-90.

10. Foley RN, Collins AJ. End-stage renal disease in the United States: an update from the United States Renal Data System. J Am Soc Nephrol. 2007; 18: 2644-8.

11. Jungers $P$, Joly D, Barbey F, Choukroun G, Daudon M. ESRD caused by nephrolithiasis: prevalence, mechanisms, and prevention. Am J Kidney Dis. 2004; 44: 799-805.

12. Marangella $M$, Bruno $M$, Cosseddu $D$, Manganaro $M$, Tricerri $A$, Vitale $C$, et al. Prevalence of chronic renal insufficiency in the course of idiopathic recurrent calcium stone disease: risk factors and patterns of progression. Nephron. 1990; 54: 302-6.

Source of Support: Nil. Conflict of Interest: None Declared. Copyright: (c) the author(s) and publisher. IJMRP is an official publication of Ibn Sina Academy of Medieval Medicine \& Sciences, registered in 2001 under Indian Trusts Act, 1882.

This is an open access article distributed under the terms of the Creative Commons Attribution Non-commercial License, which permits unrestricted non-commercial use, distribution, and reproduction in any medium, provided the original work is properly cited.

Cite this article as: Surendra Mehrotra, Abhay Krishna. Prevalence of Renal Stones and Complications in Study Population: A Clinical Study. Int J Med Res Prof. 2016; 2(6):11316. DOI:10.21276/ijmrp.2016.2.6.022 